\title{
IDENTIDADES E ESTEREÓTIPOS FEMININOS EM "NOSOTRAS QUE NOS QUEREMOS TANTO”, DE MARCELA SERRANO
}

\section{FEMININE IDENTITIES AND STEREOTYPES IN "NOSOTRAS QUE NOS QUEREMOS TANTO”, BY MARCELA SERRANO}

\author{
Ângela Paula Nunes FERREIRA ${ }^{1}$ \\ Cristina BONGESTAB ${ }^{2}$
}

\begin{abstract}
Resumo: A escritora chilena contemporânea Marcela Serrano possui uma vasta obra que apresenta como ponto comum o fato de apresentar protagonistas mulheres a partir de discursos feministas. Considerando a importância da sua obra no contexto latino-americano, neste artigo, nos propomos a realizar, à luz da Crítica Feminista e dos Estudos Culturais, uma leitura da narrativa Nosotras que nos queremos tanto, buscando examinar de que maneira esta obra se constitui em forma de resistência à desigualdade entre os gêneros em nosso continente. Para tanto, buscamos verificar como se manifesta a representação das mulheres e das relações de gênero na narrativa da escritora, destacando como, nesses espaços, discursos são usados para resistirem a uma cultura patriarcal e sexista que justifica e perpetua práticas intolerantes em relação às mulheres. A metodologia utilizada consiste na leitura analíticodiscursiva da narrativa, o que requer uma revisão da teoria dos Estudos Culturais e da Crítica Feminista. $\mathrm{Na}$ obra, a autora apresenta quatro personagens mulheres, Ana, Sara, Isabel e Maria que são caracterizadas a partir de identidades e estereótipos ligados ao universo feminino, desconstruindo discursos machistas e estereotipados em relação às mulheres, que por muitos séculos se fizeram presentes no discurso tradicional literário. Assim, podemos afirmar que a narrativa se constitui a partir de discursos feministas e de resistência ao modelo androcêntrico que vigorou por séculos em nossa sociedade, estendendo-se ao campo literário, responsável por violência e opressão contra as mulheres.
\end{abstract}

Palavras-chave: Serrano. Romance. Chile. Resistência. Feminista.

\begin{abstract}
The contemporary Chilean writer Marcela Serrano has a vast work that presents as a common point the fact of presenting women protagonists from feminist discourses. Considering the importance of her work in the Latin American context, in this article, we propose to carry out, in the light of the Feminist Criticism and Cultural Studies, a reading of the narrative "Nosotras que nos queremos tanto", trying to examine how this work is constituted in form of resistance to gender inequality in our continent. In order to do so, we seek to verify how the representation of women and gender relations is manifested in the narrative of the writer, highlighting how, in these spaces, discourses are used to resist a patriarchal and sexist culture that justifies and perpetuates intolerant practices in relation to women. The methodology used consists of analytic-discursive reading of the narrative, which requires a revision of the theory of Cultural Studies and Feminist Criticism. In the work, the author presents four female characters, Ana, Sara, Isabel and Maria, who are characterized by identities and stereotypes linked to the feminine universe, deconstructing sexist and stereotyped discourses in relation to women, which for many centuries were present in traditional literary discourses. Thus, we can affirm that the narrative is constituted from feminist and resistance discourses to the androcentric model that has been in force for centuries in our society, extending to the literary field, responsible for violence and oppression against women.
\end{abstract}

Keywords: Serrano. Romance. Chile. Resistance. Feminist.

\footnotetext{
${ }^{1}$ Doutoranda em Linguística pela Universidade Federal da Paraíba. E-mail: <paulanunesf@hotmail.com>.

${ }^{2}$ Doutora em Letras Neolatinas pela Universidade Federal do Rio de Janeiro. Professora efetiva de Língua Espanhola da Universidade Estadual da Paraíba. E-mail: <cristinauepb1 @ gmail.com>.
} 


\section{Introdução}

Marcela Serrano é uma escritora chilena, nascida em 1951 na Cidade de Santiago. A autora é filha de escritores, seu pai é o ensaísta Horacio Serrano e a sua mãe é a romancista Elisa Pérez Walker. Serrano cresceu rodeada por mulheres, sendo a quarta entre cinco irmãs. Ao apresentar a biografia da autora, o site escritoras.com destaca que "ha estado siempre comprometida con la realidad política de su país, siendo militante de la izquierda, y es defensora de las reivindicaciones feministas porque, como ella misma afirma, definirse feminista es definirse ser humano"3.

Ao engajar-se com os problemas políticos do seu país e com a condição da mulher latinoamericana contemporânea, a autora é considerada uma das figuras mais importantes da literatura Latino-americana na atualidade.

Sua estreia na literatura se deu apenas aos quarenta anos, com o lançamento da narrativa, Nosotras que nos queremos tanto, em que quatro mulheres de meia idade, bem resolvidas profissionalmente, passam a conversar sobre suas experiências de vida. A obra foi considerada uma das revelações do ano de 1991 e recebeu o Prêmio "Sor Juana Inés de la Cruz" e o prêmio da Feira de Livros de Guadalajara, no México, ambos no ano de 1994, como a melhor novela hispano-americana escrita por uma mulher.

Atualmente, Serrano já publicou dez narrativas que apresentam como ponto comum o fato de abordarem como tema central a condição das mulheres na contemporaneidade. De acordo com o site Biografías y vidas, "La obra de Marcela Serrano tiene como eje temático y preocupación central la condición femenina, reflejando tanto su naturaleza como su insatisfacción y las dificultades con que topa para llegar a su realización en un mundo patriarcal." "Suas narrativas abordam temas que circundam o universo feminino, marcadas pela reflexão sobre a condição das mulheres e as relações de gênero nos dias atuais, apresentadas através de protagonistas mulheres.

Apesar da importância da obra da autora, ao ser escrita por uma mulher, declaradamente feminista, abordando o universo feminino, no Brasil ainda não há nenhum trabalho específico sobre a sua produção literária. Sua obra ainda não foi abordada pela crítica especializada.

Considerando-se que a literatura também se inscreve como documento e registro da vida em sociedade em determinado contexto histórico, é imprescindível se pensar sobre a contribuição da Literatura Latino-americana atual na compreensão das relações de gênero,

\footnotetext{
${ }^{3}$ Disponível em: http://escritoras.com/escritoras/Marcela-Serrano.

${ }^{4}$ Disponível em: https://www.biografiasyvidas.com/biografia/s/serrano_marcela.htm
} 
especialmente ao tratar de recuperar e fazer ouvir aquelas vozes silenciadas pelo tempo, examinando as origens e as consequências da distribuição assimétrica do poder entre os gêneros, destacadamente no campo literário.

Pelas questões apresentadas se justifica a importância da presente pesquisa, visto que nos permitirá uma melhor compreensão de como esse tipo de ficção dialoga de modo crítico com a história para, dentro de especificidades socioculturais, revelar a realidade de subordinação da mulher latino-americana, e, por extensão, da mulher em geral, bem como, por outro lado, de resistência a toda forma de opressão feminina.

É neste sentido que traçamos como objetivo para a nossa pesquisa realizar, à luz da Crítica Feminista e dos Estudos Culturais, uma leitura da narrativa Nosotras que nos queremos tanto, da escritora feminista latino-americana contemporânea Marcela Serrano, buscando examinar de que maneira sua obra se constitui em forma de resistência à desigualdade entre os gêneros em nosso continente. Para tanto, buscaremos verificar como se manifesta a representação das mulheres e das relações de gênero na narrativa da escritora, buscando destacar, como, nesses espaços, discursos são usados para resistirem a uma cultura patriarcal e sexista que justifica e perpetua práticas intolerantes em relação às mulheres.

Isso significa que a obra de Serrano se constitui em forma de resistência à desigualdade entre os gêneros em nosso continente, a partir da representação da mulher como capaz de traçar seu próprio destino sem que seu futuro dependa da presença masculina em sua vida. A obra da autora é marcada por discursos que sugerem a independência e insubordinação das mulheres nos dias atuais, em relação aos homens.

A nossa pesquisa adota uma abordagem qualitativo-interpretativista, na medida em que se dispõe a realizar, à luz da Crítica Feminista e dos Estudos Culturais, uma leitura da obra Nosotras que nos queremos tanto, da escritora feminista latino-americana contemporânea Marcela Serrano, buscando examinar de que maneira referida obra se constitui em forma de resistência à desigualdade entre os gêneros na América latina.

De acordo com Moreira e Caleffe (2008, p. 60), "o interesse central de todas as pesquisas nesse paradigma é o significado humano da vida social e a sua elucidação e exposição pelo pesquisador." Para tanto, o pesquisador será considerado instrumento de coleta de dados e, portanto, deve ser capaz de reconhecer, classificar e distinguir as sutilezas dos significados que emergem. 


\title{
Estudos culturais e crítica feminista
}

Após a Segunda Guerra Mundial, surge na Inglaterra uma corrente de pesquisa que apresenta como ponto em comum o fato de considerar a cultura em sentido amplo, antropológico, com foco numa abordagem da cultura dos grupos sociais excluídos, a qual foi denominada Cultural Studies.

De acordo com Mattelant e Neveu (2004, p. 14),

\begin{abstract}
Mesmo que ela permaneça fixada sobre uma dimensão política, a questão central é compreender em que a cultura de um grupo, e inicialmente a das classes populares, funciona como contestação da ordem social ou, contrariamente, como modo de adesão às relações de poder.
\end{abstract}

Cultural Studies surge inicialmente na Inglaterra como um núcleo marginal de pesquisa, no entanto, no ano de 1980 começa a apresentar uma notável ampliação. As análises fomentadas entre universitários e a nova esquerda britânica passam a abarcar temas relacionados ao "gênero", a "etnias" etc., e aos poucos se propagam em nível mundial. Neste contexto, surgem discussões acerca da questão da identidade vigente à época, especificamente da identidade nacional, vindo o estudo da identidade e a indagação acerca da sua rigidez e estabilidade que prevalecia até meados do século XIX a se tornar temática primordial dos Estudos Culturais.

A identidade, entendida até o século XIX de forma rígida e muitas vezes dicotômica, torna-se objeto de investigação dos Estudos Culturais na medida que, o enfraquecimento do Estado-nação e o processo de globalização torna-se um problema, surgindo como uma forma de mudança radical e irreversível da sociedade, afetando as estruturas estatais, as condições de trabalho, as relações entre os Estados, a subjetividade coletiva, a produção cultural, a vida cotidiana e as relações entre o eu e o outro. A temática da identidade se coloca na contemporaneidade, à medida que se apresenta como um problema na conjuntura social da segunda metade do século XIX.

Na Idade Moderna, encontrávamos identidades rígidas, que de certa forma estabilizavam o mundo social, a partir de conceitos estáticos e bastante delimitados. Porém, a partir de meados do século XX, a identidade começou a deixar de ser encarada como um conceito estático ou como sendo produto da natureza, mas sim como um conceito dinâmico, variável e produzido a partir de elementos culturais.

Considerando-se esta realidade, numa sociedade que tornou variáveis e efêmeras as identidades sociais, culturais e sexuais, tentativas de torná-las rígidas acabam sendo responsáveis pela formulação de estereótipos. 
Sobre os estereótipos, é possível afirmar que inclusive o termo "feminista" cotidianamente é utilizado de forma negativa e estereotipada. Em obra intitulada Sejamos todos feministas, Adichie (2015, p. 8) enfatiza que "a palavra 'feminista', como a própria ideia de feminismo, também é limitada por estereótipos”.

Na mesma linha de pensamento do filósofo francês Michel Foucault de que não se pode pensar qualquer coisa em qualquer momento, uma vez que pensamos apenas nas fronteiras do discurso do momento, Veyne (2011, p. 49) afirma que "sempre somos prisioneiros de um aquário do qual nem sequer percebemos as paredes; como os discursos são incontornáveis, não se pode, por uma graça especial, avistar a verdade verdadeira, nem mesmo uma futura verdade ou algo que se pretenda como tal."

Desta maneira, são os discursos que nos permitem estabelecer determinadas identidades ou estereótipos, uma vez que as identidades são produzidas nos discursos e através deles, a exemplo do estereótipo negativo historicamente ligado ao termo "feminista" ou "feminismo".

De acordo com Bauman (2008), as modificações trazidas pela modernidade transformaram a identidade em uma categoria líquida, pois individualmente é possível pertencer a vários grupos sociais, por isso, temos várias identidades decorrentes da representação de instituições como o Estado, a família, a religião. Não somos expostos a apenas uma comunidade de ideias e princípios por vez, mas a muitas delas de forma simultânea, o que origina uma condição sempre provisória da identidade.

No caso da tradição literária, durante muito tempo as mulheres foram apresentadas como dóceis, românticas, mocinhas inspiradoras, sustentando uma imagem feminina completamente arraigada no imaginário masculino, justificando e perpetuando práticas intolerantes e estereotipadas em relação às mulheres que são colocadas à margem da ordem do discurso literário, acatadas com naturalidade pela sociedade, sem se considerar inclusive que não existe unicidade na categoria "mulheres".

Na década de 1970, surge nos Estados Unidos da América, com a publicação da obra Sexual politics, de Kate Millet, a crítica literária feminista, com o objetivo inicial de "tentar romper com os discursos sacralizados pela tradição, nos quais a mulher ocupa, à sua revelia, um lugar secundário em relação ao lugar ocupado pelo homem, marcado pela marginalidade, pela submissão e pela resignação" (ZOLIN, 2009, p. 239).

A crítica literária feminista se insurge contra a prática acadêmica patriarcal e enfatiza a posição social da mulher e sua presença no universo literário, denunciando o espaço relegado à mulher na sociedade, e suas consequências no âmbito literário.

Ela se origina através do movimento político e social denominado feminismo. O 
movimento feminista organizado surgiu nos EUA, na segunda metade dos anos 60, expandindose pelos países do Ocidente, propagando ideias voltadas à libertação da mulher, de modo a afirmá-la como indivíduo autônomo, independente, dotado de plenitude humana e tão sujeito frente ao homem quanto o homem frente à mulher.

É diante desta realidade que, timidamente, vão surgindo, sobretudo na Europa e na América uma literatura escrita por mulheres que buscava desconstruir a representação tradicional da mulher na literatura, opondo-se a uma literatura de escrita masculina.

Superando o estágio inicial, insurgem novos problemas para serem enfrentados pela crítica feminista contemporânea. O principal deles consiste na consciência de que não existe uma identidade feminina única.

Bauman (2008, p. 22) afirma que "no admirável mundo novo das oportunidades fugazes e das seguranças frágeis, as identidades ao estilo antigo, rígidas e inegociáveis, simplesmente não funcionam." Desta maneira, a identidade apresenta-se como elemento complexo e por isso objeto de reflexões em vários campos de estudos a exemplo da Antropologia, da Sociologia, da Filosofia.

De acordo com Hall (2006), a identidade apresenta-se como um processo que se desenvolve e se transforma com a história, de acordo com as concepções de sujeito do Iluminismo, sujeito da Modernidade e sujeito da Pós-modernidade.

O autor destaca que, a partir de uma visão pós-moderna de sujeito fragmentado, composto não de uma, mas de várias identidades, inclusive contraditórias, que tentam acompanhar as mudanças constantes, rápidas e permanentes da sociedade, a identidade passou a ser vista como algo histórico e não biológico.

As identidades produzidas a partir de oposições dicotômicas territoriais, nacionais, de gênero, são canceladas, momento em que "as identidades ganharam livre curso, e agora cabe a cada indivíduo, homem ou mulher, capturá-las em pleno voo, usando os seus próprios recursos e ferramentas" (BAUMAN, 2008, p. 85), não podendo mais ser ocultadas a fragilidade e a condição eternamente provisória da identidade.

É partindo do pressuposto de que não existe uma identidade feminina, mas identidades múltiplas, articuladas a outras relações sociais, tais como raça, classe, etnia, que surge a necessidade de leitura e análise de textos de autoria feminina não-eurocêntricos, pois, compreensão das diferenças inerentes às mulheres dos países antes colonizados, a crítica feminista torna-se uma espécie de cúmplice de certas ideologias racistas e colonialistas. (ZOLIN, 2009, p.237). 
É nesse contexto que surge o interesse pelos textos de autoria feminina latino-americanos, na busca de representações múltiplas e heterogêneas das demandas femininas através da literatura.

\section{Produção literária feminina na América Latina}

Durante muitos séculos, o cânone literário mundial privilegiou os textos produzidos por homens, brancos e ricos. Assim, as mulheres, os negros e outras "minorias" se viram excluídos da crítica literária, dos estudos acadêmicos, das editoras, do cânone literário etc.

Por motivos antropológicos, sociológicos e históricos, a mulher foi excluída do mundo da escrita. De acordo com Lobo (1997, p. 3), “a literatura foi até este século uma atividade masculina, regida por princípios patriarcais e falocêntricos.” As mulheres só puderam introduzir seu nome na história da escrita através de tênues oportunidades que conseguiram abrir através de seu aprendizado de ler e escrever em conventos, de forma bastante discreta. Na América Latina, podemos destacar a Madre Francisca Josefa del Castillo (1671-1742), na Colômbia. No México, a freira Sór Juana Inês de la Cruz (1648-1695). Em Cuba, Gertrudis Gómez de Avellaneda (1814-1873).

No entanto, a partir da década de 1960, com o movimento feminista que surge como resistência a todas as formas de subordinação do feminino, com as reflexões acerca do Direito ao próprio corpo e o questionamento da existência social, com o notável e inédito acesso das mulheres à universidade e ao mercado de trabalho, o desejo de se tornarem ouvidas se tornou mais intenso. As escritoras passaram a expressar suas realidades psicológicas, filosóficas, seus medos e anseios ultrapassando um período inicial em que se limitavam a repetir o estilo dos homens, no século XIX, quando conseguiram entrar no mundo literário.

De acordo com Stuart Hall, em A identidade cultural na pós-modernidade:

[o] feminismo faz parte daquele grupo de 'novos movimentos sociais', que emergiram durante os anos sessenta [...] juntamente com as revoltas estudantis, os movimentos juvenis contraculturais e antibelicistas, as lutas pelos direitos civis, os movimentos revolucionários do "Terceiro Mundo", os movimentos pela paz... (HALL, 2006, p. 44).

O movimento feminista, ao abordar questões peculiares ligadas à condição da mulher, destacando-se os Direitos Políticos e trabalhistas, Direitos sexuais e reprodutivos, lutando por legislações igualitárias e diminuição da violência contra a mulher, contribuíram para a inclusão 
da questão de gênero como uma das desigualdades a serem superadas por um regime democrático.

Neste contexto, a literatura escrita por mulheres começou a criar um espaço próprio dentro do universo da literatura mundial mais ampla, oportunidade em que a mulher passou a expressar-se a partir de um ponto de vista e de um sujeito de representação próprios, constituindo um olhar da diferença ao retratar as vivências da mulher a partir de um olhar peculiar.

Destaca-se que "não basta um objeto ligado à experiência da mulher ou ser-se do sexo feminino para tornar o texto feminista, o que torna um texto feminista é o seu ponto de vista" (MOI, 1988, p.120). Desta forma, o texto literário feminista se enquadra pelo seu engajamento na luta contra toda e qualquer forma de patriarcalismo e sexismo.

As obras literárias latino-americanas escritas por mulheres, publicadas nos últimos anos se caracterizam, em grande parte, por assumirem o discurso feminista que consolida as forças rumo à desconstrução de discursos que sustentavam a subordinação da mulher.

Em ensaio intitulado “A literatura de autoria feminina na América Latina”, Lobo (1997) afirma que as obras deste período não apenas desnudam, e assim contribuem para diminuir a desigual distribuição de poder nas relações entre gêneros, mas também sublinham a necessidade urgente de revisar uma história que se caracterizou pelo privilégio do gênero masculino, pela exclusão das outras raças que não fossem a branca, e pelo desprezo das classes sociais baixas. Ao incorporar as vozes antes marginalizadas, os romances reescrevem a história, procurando recuperar a(s) identidade(s) daqueles que sempre foram apenas objeto na narrativa, nunca autores. Assim, a escrita feminista implica um corte em relação às ideias hegemônicas na sociedade patriarcal que se apresenta como de resistência feminista.

Neste contexto, podemos destacar a obra da escritora latino-americana contemporânea Marcela Serrano por seu caráter de resistência a esses discursos perpetuados durante séculos em nossa sociedade, propagadores de estereótipos e preconceitos, ao apresentar identidades que se contrapõem aos modelos femininos apresentados na literatura ao longo do tempo.

\section{O romance Nosotras que nos queremos tanto como produção de resistência feminista na}

\section{América Latina}

O enredo de Nosotras que nos queremos tanto se passa em uma casa, à beira de um lago, no sul do Chile, alugada pela personagem Ana para passar as férias e reencontrar suas amigas Maria, Isabel e Sara. A casa de madeira branca, com dois andares, está localizada em uma ilha, 
e só é possível se aproximar do povoado mais perto se utilizando de um bote a remo ou através da lancha de um ex-pescador, Sr. Manoel, grande conhecedor da região. O imóvel pertence a Senhora Wilson, que pobre e viúva, é obrigada a alugar a casa a desconhecidos para ajudar na renda. Ao descrever o imóvel, ainda no primeiro capítulo, Ana nos surpreende com a fala de Sara que se revolta ao perceber que a arquitetura da casa estava visivelmente a serviço do modelo patriarcal, que tem no maior quarto, uma grande cama de casal, reservada ao homem e sua companheira. Podemos afirmar que este é o primeiro discurso de resistência presente na obra.

\footnotetext{
'Por Deus, Ana' - diria mais tarde Sara, revoltada - 'você já ouviu falar de arquitetos especializados em imaginar espaços destinados a mulheres solitárias? Somos muitas, mas parece que não somos vistas como um dos segmentos do mercado.' A existência de um privilegiado homem da casa pode ser percebida na arquitetura e na decoração. (SERRANO, 2011, p.11-12).
}

A invisibilidade das mulheres solitárias é denunciada nesta fala de Sara. A forte influência do clássico feminista de Virginia Woolf Um teto todo seu se evidencia desde o primeiro capítulo da narrativa, a partir da indagação sobre a divisão tradicional das casas, sempre colocando o homem em posição de destaque, como se não fosse possível uma mulher sozinha ser proprietária de sua moradoria.

A obra Um teto todo seu é um ensaio baseado em dois artigos apresentados por Virginia Woolf em duas faculdades inglesas exclusivas para mulheres a partir da temática "As mulheres e a ficção.” Em suas palestras que deram origem ao ensaio, a autora revela como a ausência de autonomia financeira e de legitimidade cultural é prejudicial ao trabalho de escrita literária das mulheres. Para confirmar sua tese, a autora compara as condições de produção literária do famoso escritor Shakespeare e de uma possível irmã que o referido tivesse, mesmo que ambos possuíssem iguais aptidões para a escrita, demonstrando que às mulheres são negadas a possibilidade de desenvolver seus potenciais criativos e por isso não há nomes femininos de destaque na literatura da época, na mesma proporção de homens escritores.

Assim é que Woolf defende que para que a mulher consiga escrever em condições de igualdade com os homens e possa expressar livremente seu pensamento sem sujeição e que seja respeitada é indispensável que possua "um teto todo seu."

A obra que iremos analisar, Nosotras que nos queremos tanto, é narrada em primeira pessoa, pela narradora-personagem "Ana", uma das quatro personagens protagonistas. Desta maneira, considerando a importância e protagonismo destas quatro amigas que se reencontram, tendo como anfitriã a personagem “Ana”, realizaremos a análise da obra, a partir destas quatro 
figuras emblemáticas, iniciando-se pela narradora-personagem Ana, seguindo-se de Sara, Isabel e por fim, Maria.

\title{
Ana: a narradora anfitria
}

No capítulo 1, Ana se apresenta como sendo a mais velha entre as amigas, ao preparar-se para recebê-las em sua casa de verão. A visita das amigas desperta em Ana um misto de alegria e medo: "Não sabe que, além de entusiasmo, sinto um pouco de medo. Aconteceram tantas coisas!” (SERRANO, 2011, p. 9). Além do Sr. Manoel, Ana conta com a ajuda de Carmen, que vive a cem metros dali para cuidar da casa. Ana se apresenta da seguinte maneira:

\begin{abstract}
Tenho cinquenta e dois anos e um marido muito estudioso, eterno professor universitário, que sempre atuou na área das letras. Ele resolveu, tardiamente, fazer um doutorado na Alemanha, e hoje deve estar passando muito frio em Heidelberg, enquanto aproveito esse tão esperado verão. Tenho três filhos, dois homens e uma mulher, e três netos. Fui professora de literatura durante muitos anos. Casei-me muito jovem e ainda amo o meu marido. Sou de natureza monogâmica e estabeleço relações quase maternais com os homens. [...] Você sabe que a soma de dois salários de professor não dá para enriquecer, mas mesmo assim me permiti certos luxos, como, por exemplo, fazer um mestrado nos Estados Unidos, quando já estava casada e era mãe de família. Isabel sempre me pergunta como consegui me afastar das crianças por quase um ano; e eu lhes respondo que me afastei, e sobrevivi. (Ibid., p.13).
\end{abstract}

Ana inicia sua apresentação se aproximando do discurso tradicionalista do que se espera de uma mulher da sua faixa etária, casada, com filhos e netos. No entanto, em sua apresentação inicial, já é possível perceber que há um desejo de se romper com um dos estereótipos, do qual as mulheres estiveram submetidas ao longo da história que é "o mito do amor materno". O modelo de maternidade oferecido pela tradição ocidental, estereotipado como universal, supõe e exige comportamentos e sentimentos de renúncia, ternura, amor incondicional por parte de todas as mulheres mães, diretamente associado à figura bíblica da "Virgem Maria", segundo a qual a mãe está disposta a sofrer e viver em razão da sua maternidade.

Badinter (1985, p.21) em obra intitulada Um amor conquistado: o mito do amor materno, se opõe ao fato de que em nossa sociedade

mesmo reconhecendo que as atitudes maternas não pertencem ao domínio do instinto, continua-se a pensar que o amor da mãe pelo filho é tão forte e quase geral que o provavelmente deve alguma coisinha à natureza. Mudou-se o vocabulário, mas conservaram-se as ilusões. 
A personagem "Ana" tem uma família tradicional e ressalta ser feliz vivendo nesta condição, no entanto, ainda nesta exposição, apresenta duas situações que quebram com este paradigma de mulher exemplar tradicional. Primeiro, o fato de atualmente se encontrar distante do esposo, que se encontra estudando na Alemanha. E ainda, o fato de ter se afastado dos filhos por cerca de um ano, na época em que fez mestrado nos EUA. Esta situação desperta a atenção de sua amiga Isabel, pois, neste ponto, Ana se distancia do estereótipo de mãe ideal, sempre presente na vida dos filhos, que os tem sempre como prioridade, e que não se afasta deles por motivo algum.

Ao se apresentar como escritora e destacar seus interesses, Ana ressalta que "a literatura e a singularidade do gênero feminino talvez sejam os mais importantes" (SERRANO, 2011, p.13).

Esta afirmação faz-nos associar a personagem "Ana" com a própria autora Marcela Serrano, a qual, a partir de uma análise de sua biografia, podemos afirmar que comunga da mesma ideia e interesse pelas especificidades do gênero feminino.

No capítulo 2, Ana narra como conheceu as amigas Isabel e Sara, há dez anos, em uma reunião de um novo Instituto de Pesquisas a convite da personagem Dora, do qual, em seguida, Maria também faria parte. A narradora inicia o capítulo apresentando uma situação inusitada, o fato de estar voltando àquela casa, desta vez sozinha, sem a companhia do seu marido Juan, de seus filhos e netos, o que destoa de sua prática tradicional de sempre estar acompanhada do esposo e dos filhos.

Ao apresentar a amiga Isabel a partir do dia que a conheceu, à época grávida, a maternidade é apresentada de uma forma negativa e não romantizada, no momento em que Ana ao observar a nova colega pensa: "Imaginei as náuseas matinais, as crises frequentes de azia, e agradeci à vida por já ter superado esta etapa" (Ibid., p.17).

Neste capítulo, Isabel e Sara são apresentadas de maneira superficial, já que são caracterizadas a partir das lembranças de Ana acerca do primeiro encontro do grupo do qual fariam parte. Nesta descrição inicial, se destaca a beleza de Isabel e o fato de ter sido estereotipada por Ana, como "um modelito convencional em todo o seu esplendor.", devido a sua beleza, suas vestes e ao fato dela ter estudado em uma Universidade Católica.

Por sua vez, Sara é apresentada: "Nada dela chamava muito atenção. Uma mulher comum" (Ibid., p.19), como alguém confiável e eficiente. Neste capítulo, podemos analisar as impressões iniciais que uma mulher causa em outra, em um primeiro encontro, e como são criados estereótipos a partir da aparência física de cada uma. 
Sobre a ausência dos familiares no encontro, Isabel curiosamente indaga surpresa a Ana: "Você está bem? Está sentindo muita falta do Juan?" (SERRANO, 2011, p.22)

A este questionamento, contraditoriamente, Ana que após tantos anos de casada se autointitula apaixonada pelo marido responde: "- Estou melhor do que nunca. Juan sempre me faz falta, mas a solidão é um bálsamo." Sobre a falta dos filhos, Ana afirma que "todas as mães merecem umas férias de vez em quando. Além do mais, já são grandes” (Ibid., 23).

Da mesma forma que Ana se adequa ao modelo patriarcal de mulher casada, com filhos e netos, que após anos de casada continua amando o marido, se afasta do arquétipo de mulher e mãe exemplar, que sempre está ao lado do esposo e dos filhos, para mostrar que em duas oportunidades em sua vida, quando mais jovem e foi fazer o mestrado nos EUA e atualmente, naquele momento de reencontro com as amigas, se distancia dos filhos sem ver isso como algo negativo. Ana representa as mulheres da atualidade, que não abdicam do desejo de ser esposas e mães, porém, não deixam que essas posições a afastem da realização dos seus sonhos e desejos outros, além do tradicional matrimônio e maternidade.

Ainda na biografia de Ana, há outro fato bastante importante que a afasta do padrão de esposa e mãe exemplar patriarcal. Em sua passagem de nove meses pelos EUA, onde fez seu mestrado, Ana compreendeu "uma série de coisas sobre o desejo feminino. Como era preparado para ser um dos sentimentos, como era fácil reprimi-lo sem maiores custos aparentes, como era escassa a sua autonomia" (Ibid., p. 218).

Foi a partir desta compreensão, que Ana conseguiu ficar meses longe dos filhos e do marido, sem se relacionar com outro homem, até que acabou se envolvendo com Hélio, um vizinho brasileiro, com quem construiu uma relação platônica, repleta de amor e compreensão. No entanto, no dia da sua partida de volta para o Chile, acabou cedendo ao seu desejo e passou a noite com Hélio. No dia seguinte, voltou ao Chile, e ao encontrar o marido, tornou a relacionar-se normalmente com ele, até surpreendentemente descobrir que estava grávida de uma menina. A dúvida sobre a paternidade da filha caçula, e a traição do marido são segredos que Ana carrega ao longo dos anos e faz com que esta seja mais uma entre tantas mulheres, que não se adéquam ao estereótipo androcêntrico de esposa perfeita.

\section{Sara: a profissional irrepreensível}

No capítulo seis, nos é apresentada a personagem "Sara", engenheira civil, mãe de "Roberta", vinda de uma família radicada do interior, e que sempre viveu e foi criada exclusivamente por mulheres. 
O pai de Sara abandonou a mãe um mês antes do seu nascimento, desta forma, ela foi criada na casa da avó materna, pela mãe e tias solteironas. A família de Sara tinha como uma de suas fontes de renda o aluguel de um quartinho a universitários. Foi através de um inquilino do quartinho que Sara conheceu o amor, o sexo, a política, enveredando por um destino diferente da mãe e tias.

Sara é caracterizada pelo fato de que nunca levou a sério os conselhos tradicionalistas das tias, "Nunca as levara a sério, mesmo amando-as muito. É que Sara nasceu com a sorte de não levar muito a sério a opinião de ninguém quando tomava uma decisão" (SERRANO, 2011, p. 48).

Esta forma de Sara viver, sem se preocupar com estereótipos, se mostra presente ao longo da narrativa, destacando-se o fato de ter escolhido uma profissão inicialmente tida com masculina, ser mãe solteira, e não se preocupar com a filha como, em regra, as outras mães se preocupam com os filhos.

A mãe de "Sara", "Dona Lucy", "foi costurar, porque tinha uma filha para educar" (Ibid., p.46), enquanto isso, sua irmã "Elvira tinha um salário de professora, pois trabalhava em uma escola próxima". As duas irmãs mais velhas, Elsa e Adela, "faziam doces [...] Usavam as ameixas do quintal e as maçãs da horta de Tia Rosa" (Ibid., p. 47).

Apesar de viver cercada por mulheres que exerciam atividades tipicamente femininas, Sara de forma inovadora escolhe ser engenheira civil, atividade predominantemente masculina, o que choca a família, como podemos perceber no seguinte trecho: “Quando Sara anunciou que seguiria uma carreira, as tias ficaram apavoradas. Para quê? era a pergunta que vinha do fundo dos seus corações" (Ibid., p. 48).

E foi a partir desta decisão, que Sara resolve romper com a tradição familiar, deixando as tias chocadas.

Em Profissões para mulheres e outros artigos feministas, a escritora inglesa Virginia Woolf afirma que:

\footnotetext{
ainda vai levar muito tempo até que uma mulher possa se sentar e escrever um livro sem encontrar com um fantasma que precise matar, uma rocha que precise enfrentar. E se é assim na literatura, a profissão mais livre de todas para as mulheres, quem dirá nas novas profissões que agora vocês estão exercendo pela primeira vez (WOOLF, 2016, p. 17).
}

Esta dificuldade em exercer profissões historicamente tidas como masculinas, prevista por Woolf em 1931, foi enfrentada, sobretudo a partir da década de 70, momento em que as mulheres começaram a adentrar no mercado de trabalho e a encarar atividades distintas das 
tradicionalmente tidas como femininas. É nesse contexto que se insere a personagem Sara, que na obra bem exemplifica algumas destas "rochas" que precisou enfrentar até tornar-se engenheira civil.

No que diz respeito à relação com o sexo oposto, o desenrolar do enredo aponta que Sara, em sua relação com o pai da sua filha, "Francisco", teve um momento inicial de subserviência que a assemelhava a maioria das mulheres da sua época:

Sara cozinhava para aquela pequena multidão, com gentileza e alegria, e dava uma clara preferência aos gostos de Francisco. Como gostava de agradá-lo! Aceitou até mudar sua receita de talharim e trocar o orégano- para ela sagrado-pelo louro, porque era assim que ele preferia. Aprendeu a cozinhar tripas, outros tipos de miúdos, pé de porco, tudo o que os homens pediam (SERRANO, 2011, p. 98).

No entanto, apesar de Sara ter dedicado todas as suas energias a tornar a vida de Francisco, em tempos de ditadura, mais suportável, o marido encontra como saída para seus problemas a busca por "outras mulheres."

Sara vivia ao lado de Francisco uma relação marcada pela opressão e inclusive violência sexual, pois era obrigada a utilizar algum método contraceptivo, já que Francisco não queria ter filho, além de uma relação marcada pela traição do companheiro.

Lembro-me da época em que Francisco não queria que tivéssemos filhos. As pílulas me faziam mal e nenhuma outra coisa funcionava comigo, mas como era ele que se recusava a ter filhos, pedi-lhe que fizesse uma vasectomia. Seu não foi categórico. Pediu-me para ligar as trompas. Quando, finalmente, consegui obrigá-lo a me explicar qual era a verdadeira causa da recusa, confessou que, psicologicamente, precisava se sentir sempre fértil. Alegou que a operação poderia prejudicar sua masculinidade, e, por último, disse que se nossa relação fracassasse e, já velho, se arrependesse de nunca ter tido filhos, poderia tê-los com uma mulher mais jovem. Ou seja, a fertilidade dele era mais importante do que a minha. Achava que todo o problema da contracepção era MEU (Ibid., p. 252).

A mais grave afronta à liberdade sexual e Direitos reprodutivos de Sara se deu na oportunidade em que ela descobriu que estava grávida de Francisco.

Era uma mulher cheia de amor, sempre havia sonhado com a maternidade, mas adiara seu sonho para atender ao homem que havia escolhido. Discutiram assunto mil vezes. Entre uma discussão e outra, ela engravidou. Ele sugeriu que abortasse (não seria a primeira vez) e ela se negou. Francisco estava prestes a fazer uma viagem- uma das muitas que fazia para o partido- e ficaram de tomar uma decisão quando ele voltasse. Mas, na sua ausência, Sara ficou sabendo que a ex-amiga Pilar acabara de parir no Chile. O pai do bebê era Francisco (SERRANO, 2011, p. 103). 
Depois desta ocasião, em que Sara se vê duplamente agredida por Francisco, primeiro por querer obrigá-la a abortar e segundo por tê-la traído e engravidado outra mulher, a relação chegou ao fim, após Francisco ter simplesmente a abandonado.

A partir da relação entre Sara e Francisco, a narrativa denuncia uma situação que afronta os Direitos sexuais e reprodutivos das mulheres, muito frequente em relações marcadas pelo poderio masculino, que é o fato de o homem colocar toda a responsabilidade acerca dos cuidados da contracepção, sobre a mulher. E ainda, culpá-la pela falha na utilização de algum método, como se a responsabilidade fosse exclusivamente da mulher.

No momento em que Sara relembra estes fatos que marcaram sua vida, após muitos anos, ao reencontrar as amigas na casa do lago, conclui que

- Você quer perguntar uma outra coisa: como aguentei tanto a mim mesma? FOI CULPA MINHA. É por isso que encerrei o capítulo casamento. É que, quando me apaixono, perco toda a dignidade. É que sou um ser humano que foi capaz de viver o que vivi por opção. Tenho vergonha da Sara daquela época, pois fui eu quem permitiu que acontecesse comigo tudo o que aconteceu (Ibid., p.104).

Sara mais uma vez destoa do pensamento comum a muitas mulheres, de se perturbarem pelo fato de que vão envelhecer e com isso não serão tão desejadas pelos homens, e inclusive em muitos casos serão trocadas como objetos por mulheres mais jovens e sedutoras. A esta realidade, Sara responde a partir de um pensamento e conduta bastante racional. "Não colocar a segurança na sexualidade e nem nas coisas externas. Ou seja, em nada que se extinga com o avanço da idade" (Ibid., p. 248).

De forma definitiva, Sara se auto impõe um celibato, sob o argumento de que: "É porque sou uma exceção que não gostaria de me distrair com coisas do coração. Para mulheres normais, como Ana, elas são perfeitamente compatíveis. Mas, para as anormais, como eu-ri- são quase contraditórias" (Ibid., p. 278).

A representação da mulher, a partir da personagem "Sara" é marcada por ir de encontro há vários estereótipos sobre o feminino. O primeiro deles é acerca da importância dada pela mulher a sua beleza, o segundo é sobre a arcaica dicotomia entre profissões femininas $\mathrm{x}$ profissões masculinas, e por fim, ainda temos a desmistificação do amor materno incondicional e, sobretudo da dependência feminina em relação à presença masculina em suas vidas.

Entre a instabilidade amorosa que muitas vezes afeta todos os setores da vida da mulher e sua vida profissional, Sara faz uma opção cética: "Não trocaria um romance por um minuto sequer da minha tranquilidade. Preciso muito dela para trabalhar direito" (SERRANO, 2011, p. 275). 
Isabel: "O anjo do lar"

No sétimo capítulo, a personagem destaque é "Isabel" que se apresenta de forma dicotômica em relação à personagem Sara. Isabel se enquadra no modelo de maternidade idealizado pela sociedade, através do qual a mulher vive em função dos filhos.

\footnotetext{
Isabel vai ao colégio, ao ginásio, à quadra de tênis, à academia de dança, ao laboratório de química, volta ao tênis, vai à oficina de música, atendendo sempre com precisão aos diferentes horários de entrada e saída. Ela não se queixa. Ao contrário, estimula os filhos a praticar todas essas atividades [...] Às oito e meia, janta com as crianças na imensa cozinha toda branca que é o orgulho de Isabel (Ibid., p. 54).
}

Isabel, diferente das amigas, se encaixa perfeitamente no modelo tradicional de mulher “dona do lar", mãe e esposa, que tem como maior orgulho a sua "cozinha” impecável.

Em Profissão para mulheres, artigo lido para a Sociedade Nacional de Auxílio às Mulheres em 21 de janeiro de 1931, Woolf (2016) afirma que apesar da relativa facilidade que teve de se tornar escritora, devido ao preço baixo do papel, para escrever, seria necessário combater um certo fantasma, "o fantasma era uma mulher, e quando a conheci melhor, dei a ela o nome de heroína de um famoso poema 'O anjo do Lar','(WOOLF 2016, p. 11) Por analogia, podemos afirmar, que no dia a dia de praticamente todas as mulheres, sobretudo aquelas que além das atividades domésticas optam por exercer determinada profissão, elas sempre são aterrorizadas pelo "anjo do lar".

Woolf resume "anjo do lar" como sendo:

\begin{abstract}
Extremamente simpática. Imensamente encantadora. Totalmente altruísta. Excelente nas difíceis artes do convívio familiar. Sacrificava-se todos os dias. Se o almoço era frango, ela ficava com o pé; se havia ar encanado, era ali que ia se sentar - em suma, seu feitio era nunca ter opinião ou vontade própria, e preferia sempre concordar com as opiniões e vontades dos outros (Ibid., p.12).
\end{abstract}

Este anjo do lar também era responsável por exigir que ao resenhar textos de escritores homens, a mulher agisse de forma afável e meiga.

É nas condutas típicas da mulher “anjo do lar”, que esta personagem está inserida. Isabel releva a segundo plano inclusive suas amizades em valorização as do marido, como é comum a estas mulheres.

As únicas amigas íntimas de Isabel somos nós, e isso porque trabalhamos juntas. Não fosse assim, não haveria espaço para nós em sua vida. Nos finais de semana, ela encontra pessoas, mas sempre pessoas ligadas a Hernán ou à família de Hermán. Às vezes, se pergunta se foi largando as amizades pelo caminho ou até mesmo se chegou a ter amigos (SERRANO, 2011, p.57). 
Isabel tem sua importância relegada a segundo plano em relação ao marido. "O dia de Isabel nunca entra nessa conversa. Ele o descarta, sistematicamente” (Id, 2016, p. 57).

As amigas percebiam a relação de tirania que existia entre Isabel e Hernán e indagavam porque ela aceitava. "Ainda que nos acuse de exercermos uma má influência sobre ela - o que é, literalmente, correto - sente que sua força foi diminuída" (SERRANO, 2011, p. 282).

Tentavam desfazer o controle que Hernán exercia sobre ela, no entanto, até quando estava no trabalho e era surpreendida por uma ligação do marido para fazer o controle da rotina, Isabel prontamente atendia e se colocava à disposição do marido. “- Estou aqui, Hernán. Vivia há dezessete anos respondendo: estou aqui, Hernán” (Ibid., p. 148).

O marido não gostava muito das amigas de Isabel, sobretudo de Maria, responsável por emprestar-lhe alguns livros feministas. Hernán sabia do risco da mulher "abrir os olhos e enxergar a realidade de opressão que vivia.

Em certa oportunidade, depois de sofrer várias frustrações ocasionadas pela conduta fria e egoísta do marido, Isabel resolve passar uma noite sozinha em um hotel e na ocasião levou consigo um destes livros condenados pelo marido, um livro que Maria havia lhe emprestado, da norte-americana Marillyn French. Segundo Hernán, "Ler essas feministas não lhe faz bem” - Hernán olhou o livro, incomodado. "Elas lhe fazem mal. Você fica insuportável" (Ibid., p. 149).

Foi após uma das tantas atitudes de extremo desdém do marido para com Isabel em que Hernán afirma que "As mulheres estão sempre precisando de um nhenhenhém. E se sentem ofendidas quando os agradecimentos não vêm em quantidade suficiente. Por isso, eu digo que elas estão sempre na superfície, sempre atentas às formas” (Ibid., p. 262) que Isabel, que até agora vivia em função do marido e dos cinco filhos, e ainda envolvida em suas aulas como professora universitária e salas de escritório compartilhadas com mulheres, acaba surpreendentemente se envolvendo com um aluno.

Até então, “A infidelidade era uma coisa inimaginável para Isabel, como é para toda mulher que tenha permanecido em situação semelhante por muito tempo, até o dia em que simplesmente deixa de ser" (SERRANO, 2011, p. 284). No entanto, depois das empreitadas do aluno sedutor, e de toda a fria relação que vivia com o marido, Isabel acaba cedendo aos encantos do aluno.

Enquanto Hernán trata a esposa com frieza e desdém, acaba sendo descoberto por Maria em um momento de traição. "Como não vou me importar? Ele é um verdadeiro tirano com Isabel, controla-a dia e noite, acende velas à fidelidade, como se fosse a sua deusa mais venerada. Convenceu-a de que é esta a pedra angular do casamento. Machão mentiroso!” (Ibid., 
p. 289). No entanto, Maria foi convencida de que não deveria contar a Isabel sobre o ocorrido, mas por outro lado, vibrava ao saber que Isabel agora conseguia se satisfazer como mulher, em sua relação com o aluno. Em tom de brincadeira Maria contesta: "O que está acontecendo com as mulheres recatadas deste país? Todas soltaram a franga em uníssono?” (Ibid., p. 290).

No entanto, a nova vida de Isabel, dividida entre o modelo de esposa exemplar e as condutas clandestinas de mulher infiel acabou na ocasião em que viajou pela primeira vez com o amante, e o filho mais velho foi preso por estar portando drogas. Instantaneamente, o ameaçador sentimento de "anjo do lar" se fez presente e levou Isabel a se sentir extremamente culpada, o que a fez "voltar para a realidade" e se afastar da vida de aventura que vivia ao lado do aluno. Sobre o fato, Maria indaga resistentemente: “- Quando um filho começa a se drogar, a mãe abandona o trabalho, mas onde está o pai? Passou pela mente de Hernán que ele deveria trabalhar menos? - irritava-se Sara. - Por que as mulheres pagam por todos os pratos quebrados?" (Ibid., p. 297).

Após o ocorrido, Isabel volta a se dedicar exclusivamente ao marido, filhos e trabalho, mas na ocasião do reencontro na casa do lago, o desabafo de Isabel deixa evidente o quão cansativa e pesada se constitui as tarefas das mulheres casadas em nossa sociedade. "- Até que enfim! A mil quilômetros de distância! Sem filhos, sem marido, sem empregada, sem CASA!" (Ibid., p.22).

\section{Maria: a subversiva}

No momento da divisão das três amigas pelos dois quartos de visita, Maria se identifica como aquela que "Não suporto nem a presença de um marido no mesmo quarto, quanto mais a de uma de vocês! " (Ibid., p. 25), ou seja, uma mulher que acostumou-se a viver sozinha e que não consegue dividir o quarto sequer com a figura de um marido, o que seria "normal" aos olhos da sociedade. Maria é uma adepta da teoria de Woolf (2014) e assim como ela, defende a necessidade da mulher ter um teto todo seu. Esse desejo é explicitado no capítulo 22, no qual consta uma oração feita por Maria, dirigida a Virginia Woolf, depois da personagem jurar que após o término do seu casamento nunca mais dividiria a mesma casa com outro homem:

- Oh, Virginia, onde quer que você esteja, no céu ou no inferno, ou mesmo se tiver decidido permanecer no oceano gelado, ouça minha prece de gratidão. Devemos-lhe muitas coisas, mais a maior delas é ter nos dado uma habitação própria. (...) -Nunca mais vou dividir um mesmo quarto com um outro homem. Ter uma cama própria é o mínimo a que uma pessoa pode aspirar! Ela é o objeto com o qual tenho mais contato durante toda a vida, fica pelo menos oito horas por dia sob o meu corpo. Como é 
possível não poder, pelo menos, dizer: 'este lugar, este retângulo inocente é MEU? (SERRANO, 2011, p.269).

No quarto capítulo, temos uma apresentação de Maria, em que se destaca sua beleza e poder de sedução, a partir das lembranças de Ana acerca do seu primeiro encontro com a amiga, quando esta veio fazer parte do instituto como jornalista e chefe do departamento de comunicação, do qual as demais já faziam parte. No capítulo seguinte, outras características da personagem são apresentadas de forma mais detalhada, a partir da descrição da sua família.

O quinto capítulo apresenta a importância dada por uma família tradicional chilena, da qual Maria e suas irmãs Magda e Soledad, filhas dos nobres Seu Joaquim e Dona Marita faziam parte, à beleza, visto que esta era considerada uma garantia de se conseguir um bom marido. Outros atributos femininos, tais como o estudo das mulheres, também tinham como foco o alcance de um bom casamento.

A mãe de Maria era uma legítima representante do modelo de mulher obediente às regras da sociedade e da igreja. E, por conseguinte, criou as filhas para que tivessem as mesmas qualidades diante da sociedade.

\footnotetext{
As 'menininhas', como eram chamadas pela mãe, estavam destinadas a seguir um roteiro brilhante: a educação básica e média, em um bom colégio particular, católico e de língua inglesa, e a educação superior-era de bom tom que se formassem, embora não tivessem, necessariamente, que exercer uma profissão- na Universidade católica. De preferência pedagogia ou alguma coisa ligada à ideia de servir ao próximo (mas sem se se rebaixar: enfermagem, jamais). Assim, teriam uma sólida base intelectual e cultural, que lhes permitiria lidar bem com qualquer circunstância. $\mathrm{Na}$ hora do casamento, poderiam escolher entre os melhores homens da sociedade, pois entre os seus atributos havia também o de um bom dote. Seria bem cotada socialmente, não lhes faltaria savoir faire para enfrentar a vida social e o seu apoio poderia ser decisivo para o crescimento profissional dos maridos. (Ibid., p. 35).
}

Neste trecho da obra, percebemos alguns discursos tradicionais acerca da posição da mulher na sociedade, geradores de estereótipos. Dentre elas podemos destacar o fato de se mencionar que as filhas de Dona Marita deveriam seguir "profissões destinadas às mulheres", como se naturalmente existissem em oposição profissões para mulheres de um lado e profissões para homens, do outro. Além disso, a qualificação das mulheres durante muito tempo em nossa sociedade, como fica evidente no desejo de Dona Marita que suas filhas estudassem, não tinha como foco a realização pessoal e profissional das mulheres, mas era apenas mais um atributo que poderia ajudá-las a encontrar "bons maridos".

Todos os atributos das mulheres, desde a beleza física até os conhecimentos científicos deveriam ter como finalidade agradar algum homem que a quisesse como esposa. Este deveria 
ser o único e grande objetivo das mulheres. Ainda sobre a sujeição das mulheres aos homens, no trecho, há um destaque para o fato de que a qualificação da mulher poderia servir de apoio decisivo para o crescimento profissional dos maridos, ou seja, as mulheres se posicionavam em lugar de subserviência em relação aos homens, enquanto estes ocupavam lugar de destaque na sociedade, e sobretudo no âmbito profissional. Este discurso é reforçado em um trecho seguinte que traz o pensamento de Dona Marita sobre a profissão das filhas: "Elas seriam os bastidores de suas famílias, mas não ofuscariam os maridos nem deixariam que percebessem o tamanho da sua força", ratificando o desejo de subsidiariedade das filhas em relação aos maridos, dentro da família.

Acerca do casamento e a maternidade, estes "seriam vividos de tal maneira que não haveria espaço para turbulências de espírito e desassossego em suas vidas. E se, por alguma circunstância da vida - ninguém pode deixar de levar em conta esta possibilidade-, o casamento trouxesse a dor, a maternidade serviria para sublimá-la” (SERRANO, 2011, p.36).

Contrapondo-se ao destino planejado pela mãe, desde tenra idade, Maria se apresenta de modo subversivo e já entrava em confronto com os desejos da mãe:

A mãe virou a cabeça, franziu o cenho e um olhar de profundo desgosto tomou conta da sua expressão.

- Maria, pelo amor de Deus, não diga uma coisa dessas!

- Mas, mamãe, o que foi que eu disse?

- Os camponeses não são bonitos!

- Como?

- Não são, Maria. Você não pode usar para os pobres os mesmos parâmetros que usa para pessoas como a gente. Os pobres não podem ser bonitos. E ponto. (Ibid., 120).

Além do gosto por homens de outras classes sociais, Maria destoava do comportamento das moças da elite da época, pois sempre tomava a iniciativa diante de um pretendente:

\begin{abstract}
Achava aborrecido esperar e declarava-se primeiro, para o desconcerto dos homens em questão e a irritação de suas amigas, que não aprovavam nem um pouco o seu comportamento. (...) Maria compreendia que estas loucuras não podiam ser de todo públicas, naquele tempo em que quase tudo que uma menina fizesse poderia muito bem ser objeto de reprimendas. (SERRANO, 2011. p. 124).
\end{abstract}

Após os quinze anos, Maria começou a efetivamente namorar, só que também quebrando paradigmas, sempre mantinha mais de um relacionamento ao mesmo tempo. Maria não descansou na universidade. Teve múltiplas relações, sempre mais de uma ao mesmo tempo. Advogava o amor livre e jurava que nunca se casaria ou teria filhos. Desprezava enormemente os casais convencionais (Ibid., p. 125). 
Assim é que Maria representa a mais revolucionária das quatro amigas. No entanto, se na sociedade atual não é fácil afrontar os modelos impostos, muito menos no final do século XX. Na narrativa, várias situações mostram o quanto Maria sofria preconceito de homens, amigas, e da própria família, por viver de maneira autêntica, se negando a exercer os papéis historicamente estabelecidos para as mulheres, sobretudo da sua classe social. Em um episódio, nos tempos de faculdade, Maria foi xingada publicamente por um grupo de colegas homens "Esquerdista de cu arrombado! PUTA.É isso que você é. - Gritava o rapaz, como um louco. PUTA! PUTA!" (Ibid., p. 128).

Diante dos xingamentos, Maria responde resistentemente à altura: “- Posso ser puta, seus babacas, mas não fiquem achando que algum dia farei putarias com qualquer um de vocês (Ibid., p. 128).

Os companheiros que teve ao longo da vida, também não aceitavam sua forma de encarar temas que envolviam o universo feminino.

\footnotetext{
As brigas com Vicente eram cada vez mais frequentes. Ele queria ter um casamento normal, uma mulher que se dedicasse exclusivamente a ele, e pretendia ter filhos. Maria não estava disposta a nenhuma dessas três coisas. Ela continuava a defender seu direito de ter relações paralelas e se negava, categoricamente, a sequer pensar na ideia de ser mãe (Ibid., p. 129).
}

Acerca da temática maternidade, Badinter (1985) defende que o amor materno não passa de um mito, e por isso, não se encontra inscrito na natureza feminina, mas representa um sentimento como qualquer outro, que pode se fazer presente ou não, na vida de cada mulher, de forma individualizada. A personagem "Maria" e a sua falta de desejo de ser mãe, se apresenta como exemplo da teoria defendida nesta polêmica obra.

\section{Conclusão}

Em Nosotras que nos queremos tanto, a escritora Marcela Serrano, de forma explícita, ao citar a obra Um teto todo seu, de Virginia Woolf e a norte-americana feminista Marillyn French, se apropria de discursos feministas para produzir seu enredo e caracterizar suas personagens. A trama de Serrano encontra-se marcada por resistência aos estereótipos que circulam na sociedade acerca das identidades femininas.

A análise da obra Nosotras que nos queremos tanto nos permite afirmar que as personagens protagonistas, Ana, Sara, Isabel e Maria são produzidas a partir da desconstrução de estereótipos, e do desfazimento da ideia de identidade ao modelo antigo, como sendo algo estático, imutável e inafastável. As protagonistas se apresentam como mulheres típicas do início 
da década de 90 no Chile, que em algumas circunstâncias se assemelham ao modelo tradicional de boa mãe, donas do lar, esposas fiéis e obedientes, mas que se coadunando com a afirmação de Bauman (2008) de que as identidades são fluídas, em pelo menos algum momento da vida, a exemplo de Ana e Isabel, se afastam do modelo preestabelecido e agem de maneira infiel ao seu esposo, ou ainda, se sentem felizes por se afastarem dos filhos, sem se sentirem culpadas por isso.

Por outro lado, temos duas personagens, que ao longo da trama, já apresentam características que afrontam o modelo tradicional de mulher, a partir do qual esta depende da presença de um homem em sua vida para existir e a eles são fiéis e servis, e que tem a maternidade como algo praticamente divino e indispensável para todas as mulheres. É o que ocorre com Sara, que decidiu prescindir da presença de um homem em sua vida para fazê-la feliz. E Maria, que apesar de gostar da presença masculina, se caracteriza por não conseguir manter relações monogâmicas, e ainda, por não desejar ser mãe. Os principais estereótipos femininos contestados são o do mito do amor materno e o do amor monogâmico.

Na obra em comento, a personagem Ana, que consegue passar um período de estudos em outro país longe dos filhos, Isabel que se sente aliviada por conseguir se afastar temporariamente dos filhos e das tarefas domésticas, Sara que não tem a criação da filha como prioridade em sua vida e Maria que simplesmente opta por não ser mãe, quebram o modelo materno preestabelecido e visto como verdade absoluta durante séculos.

As identidades apresentadas na obra, a partir de mulheres que se dividem entre a vida afetiva, profissional, e a criação dos filhos, ou ainda que optam por não querer essa vida, se coadunam com o modelo de identidade pós-moderno defendido por Bauman (2008).

As personagens mulheres se apresentam e são construídas a partir de uma resistência feminista, pois se apresentam com características muitas vezes distintas das personagens femininas tradicionais. Estas personagens despertam os leitores para muitas práticas ainda vigentes à época, contudo já contestadas pelos movimentos feministas, como a falta de divisão dos trabalhos domésticos, o olhar preconceituoso para as mulheres que optam por não ser mães ou não viverem dentro de uma relação conjugal em que a mulher sempre está submissa ao homem, a naturalização da traição masculina e a condenação desta atitude apenas se praticada pelas mulheres, somada à exigência da monogamia apenas para mulheres, etc.

É desta maneira que a obra se apresenta como relevante denúncia da situação de subordinação vivida pelas mulheres latino-americanas na década de 90 e ainda de resistência ao modelo androcêntrico, patriarcal, machista que vigorou durante séculos em nossa sociedade, responsável por opressões e desigualdades entre homens e mulheres que também perpassou a 
literatura, através da sua representação em obras tipicamente escritas por homens, os quais descreviam as mulheres e as relações de gênero a partir de um ponto de vista masculino.

É assim que Nosostras que nos queremos tanto, publicada no início da década de 90 se apresenta como obra inovadora e de relevante valor não só literário, como também social, ao conduzir os leitores sobre uma reflexão acerca do modelo dicotômico de gêneros vigente, responsável por violação de direitos e, sobretudo opressão dos homens sobre as mulheres que apesar de todas as dificuldades, nas suas práticas cotidianas, nas relações afetivas, maternais, profissionais e sexuais ainda que a passos curtos como no caso das personagens Ana e Isabel ou a passos largos como no exemplo das personagens Sara e Maria, resistem a tais práticas e aos poucos constroem uma sociedade menos misógina e mais igualitária.

\section{Referências}

BADINTER, Elizabeth. Um amor conquistado: o mito do amor materno. Rio de Janeiro: Nova Fronteira, 1985.

BAUMAN, Zigmunt. Identidade. Entrevista a Benedito Vecchi. Trad. Bras. Carlos Alberto Medeiros. Rio de Janeiro: Jorge Editor, 2008.

CHIMAMANDA, Adichie Ngozi. Sejamos todos feministas. São Paulo: Companhia das Letras, 2015.

HALL, Stuart. A identidade cultural na pós-modernidade. Trad. Tomaz T. da Silva e Guacira L. Louro. Rio de Janeiro: DP\&A, 2006.

LE GOFF, Jacques. História e memória. Campinas: Editora da Unicamp, 1994.

LOBO, Luiza. A literatura de autoria feminina na América Latina. In.: Revista Brasil de Literatura. Rio de Janeiro, Ano I, jul.-set. 1997.

MATTELART, Armand; NEVEU, Érik. Introdução aos estudos culturais. São Paulo: Parábola, 2004.

MOI, Toril. (Org.). Sexual/textual politics: feminist literary theory. New York: Routledge, 1988, P.117-132.

MOREIRA, Herivelto, CALEFFE, Luiz Gonzaga. Metodologia da pesquisa para o professor pesquisador. Rio de Janeiro: Lamparina, 2008.

SERRANO, Marcela. Escritoras.com: Literatura escrita por mujeres. Disponível em: http://escritoras.com/escritoras/Marcela-Serrano Acesso em: 20 abr. 2016.

. Biografías y vidas. La enciclopédia biográfica en línea. Disponível em:

http://www.biografiasyvidas.com/biografia/s/serrano_marcela.html Acesso em: 21 abr. 2016. 
Nosotras que nos queremos tanto. Santiago de Chile: Los Andes, 1991.

2011.

. Nós que nos amávamos tanto. Tradução Luis Carlos Cabral. Rio de Janeiro: Record,

VEYNE, Paul. Foucault, seu pensamento, sua pessoa. Tradução Marcelo Jacques de Morais. Rio de Janeiro: Civilização Brasileira, 2011.

WOOLF, Virginia. Um teto todo seu. Trad.: Bia Nunes de Sousa. São Paulo: Tordesilhas, 2014.

Profissão para mulheres e outros artigos feministas. Tradução Alexandra Lemesson. São Paulo: L\&PM, 2016.

ZOLIN, Lúcia Osana. Crítica Feminista. In.: BONNICI, Thomas; ZOLIN, Lúcia Osana

(Orgs.). Teoria da Literatura: abordagens históricas e tendências contemporâneas. Maringá: Eduem, 2009. p.217-242.

Recebido em 31/08/2018

Aceito para publicação em 03/12/2018 